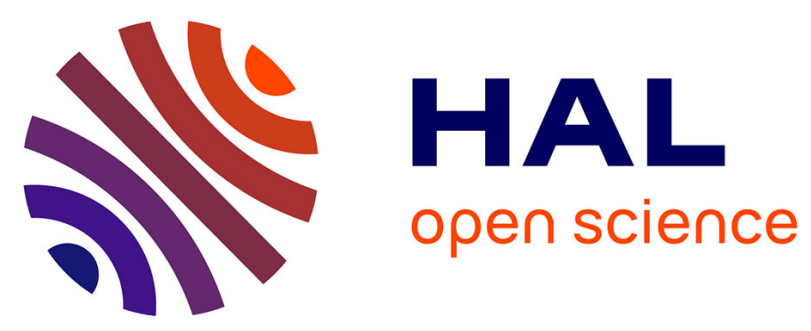

\title{
Analysis and Automatic Classification of Some Discourse Particles on a Large Set of French Spoken Corpora
}

Denis Jouvet, Katarina Bartkova, Mathilde Dargnat, Lou Lee

\section{To cite this version:}

Denis Jouvet, Katarina Bartkova, Mathilde Dargnat, Lou Lee. Analysis and Automatic Classification of Some Discourse Particles on a Large Set of French Spoken Corpora. SLSP'2017, 5th International Conference on Statistical Language and Speech Processing, Oct 2017, Le Mans, France. hal-01585567

\section{HAL Id: hal-01585567 \\ https://hal.inria.fr/hal-01585567}

Submitted on 11 Sep 2017

HAL is a multi-disciplinary open access archive for the deposit and dissemination of scientific research documents, whether they are published or not. The documents may come from teaching and research institutions in France or abroad, or from public or private research centers.
L'archive ouverte pluridisciplinaire HAL, est destinée au dépôt et à la diffusion de documents scientifiques de niveau recherche, publiés ou non, émanant des établissements d'enseignement et de recherche français ou étrangers, des laboratoires publics ou privés. 


\title{
Analysis and Automatic Classification of Some Discourse Particles on a Large Set of French Spoken Corpora
}

\author{
Denis Jouvet $^{1}$, Katarina Bartkova ${ }^{2}$, Mathilde Dargnat ${ }^{2}$, Lou Lee ${ }^{2}$ \\ ${ }^{1}$ Inria, Villers-lès-Nancy, F-54600, France \\ ${ }^{1}$ Université de Lorraine, LORIA, UMR 7503, Villers-lès-Nancy, F-54600, France \\ ${ }^{1}$ CNRS, LORIA, UMR 7503, Villers-lès-Nancy, F-54600, France \\ ${ }^{2}$ Université de Lorraine, ATILF, UMR 7118, Nancy, F-54063, France \\ ${ }^{2}$ CNRS, ATILF, UMR 7118, Nancy, F-54063, France \\ denis.jouvet@loria.fr, \{katarina.bartkova;mathilde.dargnat\}@univ-lorraine.fr, \\ lou.lee4@etu.univ-lorraine.fr
}

\begin{abstract}
In French, quite a number of words and expressions are frequently used as discourse particles in spoken language, especially in spontaneous speech. The semantic load of these words or expressions differ whether they are used as discourse particles or not. Therefore, the correct identification of their discourse function remains of great importance. In this paper the distribution of the discourse function (or not discourse function), and of the detailed discourse functions of some of these words, is studied on a large set of French corpora ranging from prepared speech (e.g. storytelling and broadcast news) to spontaneous speech (e.g. interviews and interactions between people). The paper is focused on a subset of discourse particles that are recurrent in the considered corpora. The discourse function of a few thousand occurrences of these words have been manually annotated. A statistical analysis of the functions of the words is presented and discussed with respect to the types of spoken corpora. Finally, some statistics with respect to a few prosodic correlates of the discourse particles are presented, as well as some results of automatic classification and detection of the word function (discourse particle or not) using prosodic features.
\end{abstract}

Keywords: Discourse particles, French language, Prosodic parameters, Discourse function statistics, Discourse particle detection.

\section{Introduction}

In French, some words and expressions are frequently used as Discourse Particles (DPs) in spoken language. The ongoing study aims at investigating the correlation between the main semantico-pragmatic values of the DPs and their prosodic features (pause, position in prosodic group, duration...). To not be biased by a single type of speech data, our study is based on a large variety of speech corpora that range from storytelling and prepared speech to highly spontaneous speech resulting from interactions between people. 
Studies of discourse markers, including DPs, have flourished in the last twenty years, but they most often address only the semantic, pragmatic and sometimes syntactic components of linguistic description, from a synchronic as well as diachronic point of view. However, prosodic considerations remain peripheral or quite general (see for instance $[1,2,3,4,5])$.

Using the term DP raises problems about terminology and categorization. Several terms co-exist (discourse or pragmatic markers, discourse or modal particles, phatic connectives, etc.) and they are not always interchangeable. DPs are frequently defined in contrast to discourse markers (connectives) or to modal particles $[6,7,8]$. In this paper, a DP is defined as a functional category [9], whose lexical members, in addition to being a DP, have more traditional uses (conjunction, adverb, interjection, adjective, etc.). Semantically, analyzing DPs raises the complex problem of the referential status of those items, in particular of their indexical $[10,11]$ and procedural values $[12,13]$. In short, a DP is an invariable linguistic item that functions at the discourse level: it conveys deictic information available only at utterance time. The information content can concern utterance interpretation, epistemic state and affective mood of the speaker or management of interaction.

The three items studied here behave differently, but all exist as DPs and non-DPs in French. "Alors" (then, what's up...) can be a temporal anaphoric adverb, a discourse connective or a DP. "Bon" (well, all right, OK...) can be an adjective, a noun or a DP. "Donc" (therefore, well...) can be a discourse connective or a DP. As DP, they present most of the prototypical properties listed in the scientific literature (see $[1,6,14,15]$ for some general approaches).

For conducting the study, we rely on a large variety of speech corpora coming from the ESTER2 speech recognition evaluation campaign [16] and from the ORFEO project [17]. This amounts to several millions of time aligned words. Occurrences of the selected words ("alors", "bon", "donc") have been chosen at random and then manually annotated.

The paper is organized as follows. Section 2 presents the speech corpora and the annotations. Section 3 discusses the DP vs. non-DP usage of the words with respect to the various speech corpora. Section 4 focuses on some frequent detailed discourse functions. Finally, Section 5 presents some information on a few prosodic correlates of the DPs, and Section 6 discusses some automatic classification experiments.

\section{Speech Corpora and Annotations}

The study is based on a large set of French speech corpora, of various degree of spontaneity, coming from the ESTER2 evaluation campaign [16] and the ORFEO project [17].

- Storytelling. FRE (FREnch oral narrative corpus, [18]) is a corpus of oral storytelling in French.

- News (prepared speech). EST (ESTER 2, [16]) is a corpus of French broadcast news collected from various radio channels. It contains mainly prepared speech and a few interviews. 
- Interviews, dialogues, and conversations. CFP (Corpus de Français Parlé Parisien - French spoken in Paris, $[19,20])$ contains interviews about Paris and its suburbs. COR (French part of the C-ORAL-ROM project - integrated reference corpora for spoken romance languages, [21,22]) contains dialogues and conversations as well as some more formal speech. CRF (Corpus de référence du français parlé reference corpus for spoken French, [23, 24]) contains speech recorded from speakers with various education levels. TUF refers to the French part of TUFS speech corpus [25]. And VAL refers to a part of the Valibel speech database [26].

- Interactions. CLA refers to a part of the CLAPI corpus (Corpus de LAngue Parlée en Interaction - Corpus of spoken language in interaction, [27]). FLE (a part of the FLEURON corpus, [28]) corresponds to interactions between students and other speakers (such as university staff, professors ...). TCO (TCOF: Traitement de Corpus Oraux en Français - processing French oral corpora, [29]) consists of interactions between speakers. OFR (OFROM: Corpus Oral de français de Suisse Romande - Speech corpus from French-speaking Switzerland, [30, 31]) contains data recorded during interactions and interviews. DEC (DECODA corpus, [32]) contains anonymized dialogs recorded from calls to the Paris transport authority (RATP) callcenter. Finally, HUS is a speech corpus containing recordings of working meetings.

All the corpora have been recorded in France, except VAL (recorded in Belgium) and OFR (recorded in Switzerland).

Table 1. Counts and statistics for the three studied words, for the various corpora.

\begin{tabular}{|c|c|c|c|c|c|c|c|c|c|c|c|c|c|c|}
\hline \multirow{2}{*}{\multicolumn{2}{|c|}{ Corpus }} & \multirow{2}{*}{\begin{tabular}{|l|} 
Story \\
FRE \\
\end{tabular}} & \multirow{2}{*}{\begin{tabular}{|l} 
News \\
EST
\end{tabular}} & \multicolumn{5}{|c|}{ Interviews, conversations, } & \multicolumn{6}{|c|}{ Interactions, } \\
\hline & & & & CFP & $\mathrm{COR}$ & CRF & TUF & VAL & CLA & FLE & TCO & OFR & DEC & HUS \\
\hline \multicolumn{2}{|c|}{\begin{tabular}{|c|}
$\begin{array}{c}\text { Number of words } \\
\text { (millions) }\end{array}$ \\
\end{tabular}} & 0.14 & 1.82 & 0.41 & 0.22 & 0.38 & 0.58 & 0.25 & 0.02 & 0.03 & 0.36 & 0.29 & 0.65 & 0.17 \\
\hline \multicolumn{2}{|c|}{\begin{tabular}{|c|}
$\begin{array}{c}\text { Articulation rate } \\
\text { (pho./sec.) }\end{array}$ \\
\end{tabular}} & 11.9 & 13.7 & 13.1 & 13.0 & 12.8 & 14.8 & 13.5 & 14.9 & 13.9 & 13.9 & 12.9 & 13.3 & 15.1 \\
\hline \multirow{3}{*}{\begin{tabular}{|c|}
$\begin{array}{c}\text { "alors" } \\
\text { (then, } \\
\text { what's } \\
\text { up, ...) }\end{array}$ \\
\end{tabular}} & Freq. (\%) & 0.56 & 0.16 & 0.38 & 0.39 & 0.36 & 0.24 & 0.33 & 0.23 & 0.49 & 0.38 & 0.45 & 0.79 & 0.40 \\
\hline & Nb. annot. & 98 & 172 & 87 & 86 & 91 & 84 & 77 & 35 & 73 & 71 & 91 & 66 & 79 \\
\hline & DP $(\%)$ & 24 & 55 & 79 & 77 & 68 & 67 & 71 & 63 & 93 & 75 & 84 & 79 & 89 \\
\hline \multirow{3}{*}{\begin{tabular}{|c|} 
"bon" \\
(well, \\
all right, \\
OK, ...)
\end{tabular}} & Freq. (\%) & 0.11 & 0.06 & \begin{tabular}{|l|}
0.37 \\
\end{tabular} & 0.31 & 0.52 & 0.48 & 0.38 & 0.49 & 0.30 & 0.45 & 0.23 & 0.38 & 0.45 \\
\hline & Nb. annot. & 88 & 181 & 75 & 89 & 80 & 83 & 79 & 78 & 69 & 75 & 91 & 82 & 66 \\
\hline & DP $(\%)$ & 59 & 58 & 87 & 80 & 90 & 75 & 90 & 39 & 61 & 93 & 86 & 84 & 82 \\
\hline \multirow{3}{*}{$\begin{array}{c}\text { "donc" } \\
\text { (there- } \\
\text { fore, } \\
\text { well, ...) }\end{array}$} & Freq. (\%) & 0.05 & 0.24 & 0.72 & 0.68 & 0.87 & 0.52 & 0.41 & 0.32 & 1.61 & 0.76 & 0.71 & 0.80 & 0.91 \\
\hline & \begin{tabular}{|l|}
$\mathrm{Nb}$. annot. \\
\end{tabular} & 70 & 191 & 84 & 76 & 90 & 82 & 88 & 60 & 89 & 79 & 95 & 85 & 68 \\
\hline & DP $(\%)$ & 67 & 78 & 75 & 83 & 80 & 85 & 89 & 67 & 93 & 91 & 87 & 88 & 90 \\
\hline
\end{tabular}

Except for ESTER2, which is not part of the ORFEO project, we have used the automatic speech-text alignments carried on in the ORFEO project. An in-house speehtext alignment process was applied to time align the ESTER2 data. Table 1 reports the number of words in the alignments for each corpus. Globally, for the 13 corpora, more than 5 million word occurrences have been speech-text aligned. Also, Table 1 displays 
for each selected word, its frequency of occurrence in each corpus; this vary from $0.05 \%$ for the word "donc" in the FRE corpus up to $1.61 \%$ for the word "donc" in the CLA corpus.

In each corpus, a subset of occurrences of the words "alors", "bon" and "donc" has been selected at random, and manually annotated by listening to a speech segment spanning the considered occurrence ( 15 words before and 15 words after). The manual annotation consists in indicating whether the occurrence corresponds to DP functions or non-DP functions. For DP functions, a finer annotation is made to detail the pragmatic function (e.g., concluding, rephrasing, expressing emotion, (re)introducing etc.). Incorrect data (e.g. too bad speech-text alignment) have been discarded from detailed manual annotations. Table 1 indicates for each word, the number of items annotated (either as $\mathrm{DP}$ or as non-DP).

\section{Discourse Particle or Not}

DPs do not contribute to propositional content, but they add some pragmatic function for ongoing discourse and elaborate the meaning of the utterance [33]. The three words studied here have a 'traditional' grammatical or lexical meaning, but can also convey a 'pragmatic' function when used as a DP. Non-DP "alors" is either an adverb of time (Table 2, Ex. 1) or a discourse connective. When "alors" is a DP, it no longer has its traditional meaning or function. As a DP, "alors" (re)introduces a topic, expresses speaker's emotions, attracts the interlocutors' attention, or structures the speech flow, sometimes in correlation with the cognitive process, etc. In Table 2, Ex. 2, it expresses a hesitation, not a consecutive, nor a temporal meaning. In the same way, the basic role of "bon" is an adjective; however, when "bon" is a DP it can be used to connect two discourse units.

Table 2. Examples of non-DP and DP usages for the word "alors".

\begin{tabular}{|c|l|}
\hline Ex. 1 & $\begin{array}{l}\text {.. la question que tout le monde se posait alors était les ventes de } \\
\text { ces nains de jardin refléteraient elles ... }\end{array}$ \\
Non-DP & $\begin{array}{l}\text {.. the question that everyone was asking then was would the } \\
\text { sales of these garden dwarves reflect ... }\end{array}$ \\
\hline Ex. 2 & $\begin{array}{l}\text {.. il a dit qu'il avait qu'il avait dix-huit, dix-neuf euh alors euh } \\
\text { presque dix-neuf ans ... } \\
\text { DP he said that he was that he was eighteen, nineteen ah then ah } \\
\text { almost nineteen ... }\end{array}$ \\
\hline
\end{tabular}

An interesting distributional tendency of words used as DPs is observed with respect to the type of corpus. As shown in Table 1, the frequency of DPs in the spontaneous speech (interviews or interactions) is significantly higher than in the prepared speech (storytelling or broadcast news). This is of no surprise if we accept that the main characteristics of DPs are pragmatic/deictic functions, showing speaker's intentions or emotions rather than actually conveying a lexical or a grammatical meaning. 
The word "alors" is, originally, an anaphoric adverb of time ('then' or 'at that time') as well as a discourse connective. As it can be seen in Table 1, most of the "alors" in storytelling are non-DPs. The narrative nature of this corpus can explain this distribution: "alors" is one of the favorite markers to make narration progress. However, more than $50 \%$ of the "alors" are DPs in broadcast news, and the percentage increases in interviews (around 70\%) and gets even larger for interactions (up to 93\% for FLE). The highest number of DPs "alors" are observed in the FLE, OFR, and HUS corpora. This can be explained by the fact that these corpora contain a high number of interactions between two or more speakers, and therefore a high number of turn-takings and hesitations.

As, for the word "bon", a significantly greater number of DPs are also found in spontaneous speech than in prepared speech. FRE (storytelling) and EST (broadcast news) have rather low rates of DPs (59\% and 58\%) compared to the other corpora that have over $80 \%$ of DP rates.

The word "donc" exhibits less difference between the various types of speech (spontaneous and prepared), though it has a slightly higher number of DPs in the spontaneous speech. Moreover, "donc" is the most frequent DP observed in prepared speech among the three DPs studied in this paper.

\section{Discourse Particle Function}

The DPs have been further annotated with respect to their most frequent and prominent pragmatic meanings, based on specific studies and on our annotation experience.

Table 3. Examples of some DP pragmatic functions for the word "alors".

\begin{tabular}{|l|l|}
\hline DP-introduction & $\begin{array}{l}\text {.. la les forces régulières les forces loyalistes vont mettre le paquet } \\
\text { sur bouaké [pause] alors la question qui qui se pose à la mi journée } \\
\text { c'est de savoir qui ... } \\
\text {.. the regular forces the loyalist forces will provide full backing } \\
\text { on bouaké [pause] then the question arising at midday is to know } \\
\ldots\end{array}$ \\
\hline DP-conclusion & $\begin{array}{l}\text {.. en achetant tout simplement des produits vous savez étiquetés } \\
\text { satisfait ou remboursé alors c'est une gestion mais ça marche il l'a } \\
\text { prouvé il a rempli son frigo ... } \\
\ldots \text { by simply buying products you know labeled satisfied or or } \\
\text { refunded then it is a management but it works he proved it he has } \\
\text { filled its fridge ... }\end{array}$ \\
\hline DP-interaction \\
$\begin{array}{l}\text { [Speaker1] ... et vous pensez l'avoir perdu où madame ? / [Spea- } \\
\text { ker2] alors euh j'ai deux endroits possibles alors je sais que je l'ai } \\
\text { passé au à le au métro ... } \\
\text { [speaker1] ... and you think you have lost it where madam ? / } \\
\text { [speaker2] so uh there are two possible places then I know I used } \\
\text { it at at station ... }\end{array}$
\end{tabular}


Six pragmatic functions were identified for "alors" (hesitation, introduction, reintroduction, conclusion, interaction, addition); six pragmatic functions for "bon" (conclusion, transition-confirmation, transition-dialogue, transition-incision, interruption, emotion); and five pragmatic functions for "donc" (reintroduction, introduction, conclusion, interaction, addition). Some example of DP pragmatic functions for the word "alors" are displayed in Table 3. Each DP has also a 'complex' pragmatic function when the word occurs along with one or more other DPs. This complex function is necessary as the meaning of DPs occurring in such contexts is different from the one they have when they occur alone (e.g. "bon bah" (well), "mais bon" (but OK), "enfin bon" (anyway), "bon alors" (well then), "donc voila"” (here we are), etc.).

The frequency of usage of the various DP pragmatic functions has been studied, and only the usage frequencies for the most frequent pragmatic functions are reported in Table 4, along with the number of word occurrences that were labelled 'DP' in each type of data. As it can be observed, the pragmatic functions of DPs depend on the type of corpus, whether it is prepared speech, interview, or interactions between speakers.

Table 4. Statistics for the main discursive functions.

\begin{tabular}{|c|c|c|c|c|c|c|}
\hline Word & DP function & Story & News & Interviews & Interactions & total \\
\hline \multirow{4}{*}{ "alors" } & Nb. times DP & 23 & 95 & 308 & 341 & 767 \\
\cline { 2 - 7 } & conclusion & $4 \%$ & $7 \%$ & $12 \%$ & $27 \%$ & $18 \%$ \\
\cline { 2 - 7 } & hesitation & $4 \%$ & $20 \%$ & $12 \%$ & $6 \%$ & $10 \%$ \\
\cline { 2 - 7 } & introduction & $4 \%$ & $71 \%$ & $33 \%$ & $26 \%$ & $34 \%$ \\
\cline { 2 - 7 } & reintroduction & $35 \%$ & $0 \%$ & $22 \%$ & $24 \%$ & $21 \%$ \\
\hline \multirow{4}{*}{ "bon" } & Nb. times DP & 52 & 104 & 341 & 343 & 840 \\
\cline { 2 - 7 } & complex & $33 \%$ & $11 \%$ & $35 \%$ & $43 \%$ & $35 \%$ \\
\cline { 2 - 7 } & trans.-confirm. & $27 \%$ & $26 \%$ & $19 \%$ & $17 \%$ & $20 \%$ \\
\cline { 2 - 7 } & trans.-incision & $10 \%$ & $22 \%$ & $13 \%$ & $10 \%$ & $13 \%$ \\
\hline \multirow{4}{*}{ "donc" times DP } & 47 & 149 & 346 & 414 & 956 \\
\cline { 2 - 7 } & addition & $13 \%$ & $20 \%$ & $23 \%$ & $26 \%$ & $23 \%$ \\
\cline { 2 - 7 } & conclusion & $19 \%$ & $36 \%$ & $31 \%$ & $28 \%$ & $30 \%$ \\
\cline { 2 - 7 } & reintroduction & $21 \%$ & $26 \%$ & $34 \%$ & $33 \%$ & $32 \%$ \\
\hline
\end{tabular}

The DP "alors" in spontaneous speech corpora, show more variety of usages with respect to its pragmatic functions, compared to its usage in storytelling. The highest usage percentage of the DP "alors" in storytelling corresponds the 'reintroduction' function, and in prepared speech the 'introduction' function is the most frequent.

A significant number of complex DPs are found for "bon", especially in spontaneous speech. This shows that "bon" is very often combined with other DPs, and in that case the meaning is not necessarily compositional. Less of "complex' DPs "bon" are found in prepared speech (broadcast news) compared to all the other corpora. A more formal - and less emotional - language used in broadcast news can explain this fact. Further studies are needed for complex DPs with a finer-grained analysis of their actual meanings or functions. Moreover, there are three subcategories of the pragmatic 'transition' 
function for the DP "bon": confirmation, when the speaker agrees with his interlocutor; dialogue, for simple transition between two speakers; and incision, when the speaker wants to add more information or details. The amount of transition-confirmation functions of DPs is reduced when the spontaneity degree increases.

As, for the DP “donc", the functions 'addition', 'conclusion' and 'reintroduction' have rather similar frequency in our data.

\section{Analysis of a few prosodic correlates}

In [34], prosodic correlates of a few words that can be used as discourse particles have been analyzed, but using data mainly from prepared speech. Here, as mentioned in Section 2, we consider a much larger set of speech corpora spanning various speaking styles (from storytelling to highly spontaneous speech). We report and discuss here statistics on a few prosodic correlates.

The prosodic annotation has been carried on automatically. The presence (or not) of a pause before or after the word results from the analysis of the force speech-text alignments. The segmentation of the speech stream into intonation groups is obtained with the ProsoTree software [35], which relies on F0 slope inversions as described in [36], and locates intonation group boundaries using information based on F0 slope values, pitch level and vowel duration.

Pauses before the word. Table 5 displays the percentage of occurrences of pauses before the considered word, when used as DP or as non-DP. For the word "alors", there is no difference in pause occurrences between its DP and non-DP functions in storytelling style. However, in the three remaining styles there are significantly fewer pauses before the word in non-DP than in DP functions. As far as the word "bon" is concerned, pauses before the word in non-DP functions are very few in storytelling style while their number remains significantly lower than in DP functions in the other styles too. The word "donc" has approximately the same frequency of pause occurrences before the word in DP and non-DP functions with, however, a slightly higher number of pauses in interaction data when DP.

Table 5. Percentage of occurrences of pauses before the word.

\begin{tabular}{|c|c|c|c|c|c|}
\hline Word & DP / non-DP & Story & Prepared & Interviews & Interactions \\
\hline \multirow{2}{*}{ "alors" } & DP & $82 \%$ & $79 \%$ & $63 \%$ & $62 \%$ \\
\cline { 2 - 6 } & Non_DP & $82 \%$ & $51 \%$ & $42 \%$ & $38 \%$ \\
\hline \multirow{2}{*}{ "bon" } & DP & $42 \%$ & $54 \%$ & $34 \%$ & $42 \%$ \\
\cline { 2 - 6 } & Non_DP & $3 \%$ & $10 \%$ & $7 \%$ & $14 \%$ \\
\hline \multirow{2}{*}{ "donc" } & DP & $34 \%$ & $31 \%$ & $52 \%$ & $59 \%$ \\
\cline { 2 - 6 } & Non_DP & $45 \%$ & $32 \%$ & $51 \%$ & $38 \%$ \\
\hline
\end{tabular}

Pauses after the word. With respect to the occurrences of pauses after the word (Table 6), in general, there are more pauses occurring after the DP functions of the studied words than after the non-DP functions. When a pause occurs after the word 
"bon", there are substantial differences in storytelling (high number of pause after DPs) while in the other styles the number of pauses is either very similar between DPs and non-DPs or only slightly higher in DPs. For the word "alors" the highest differences are found in "interview" and "interaction" styles (higher number of pauses after DPs). The "interaction" style is also the one where the greatest difference is found for the word "donc" (also more pauses after DPs).

Table 6. Percentage of occurrences of pauses after the word.

\begin{tabular}{|c|c|c|c|c|c|}
\hline Word & DP / non-DP & Story & Prepared & Interviews & Interactions \\
\hline \multirow{2}{*}{ "alors" } & DP & $18 \%$ & $17 \%$ & $26 \%$ & $25 \%$ \\
\cline { 2 - 6 } & Non_DP & $12 \%$ & $20 \%$ & $9 \%$ & $13 \%$ \\
\hline \multirow{2}{*}{ "bon" } & DP & $49 \%$ & $36 \%$ & $34 \%$ & $30 \%$ \\
\cline { 2 - 6 } & Non_DP & $3 \%$ & $21 \%$ & $22 \%$ & $31 \%$ \\
\hline \multirow{2}{*}{ "donc" } & DP & $12 \%$ & $20 \%$ & $25 \%$ & $24 \%$ \\
\cline { 2 - 6 } & Non_DP & $9 \%$ & $17 \%$ & $20 \%$ & $8 \%$ \\
\hline
\end{tabular}

Table 7. Position of the word in the intonation group (percentages of occurrences alone, or in first, middle or last position).

\begin{tabular}{|c|c|c|c|c|c|c|}
\hline Word & & Position & Story & Prepared & Interviews & Interactions \\
\hline \multirow{4}{*}{ "alors" } & \multirow{2}{*}{ DP } & alone & $82 \%$ & $65 \%$ & $82 \%$ & $77 \%$ \\
\hline & & first & $18 \%$ & $26 \%$ & $18 \%$ & $20 \%$ \\
\hline & \multirow{2}{*}{$\begin{array}{c}\text { Non- } \\
\text { DP }\end{array}$} & alone & $89 \%$ & $61 \%$ & $66 \%$ & $58 \%$ \\
\hline & & first & $11 \%$ & $30 \%$ & $32 \%$ & $39 \%$ \\
\hline \multirow{4}{*}{ "bon" } & \multirow{2}{*}{ DP } & alone & $67 \%$ & $78 \%$ & $63 \%$ & $66 \%$ \\
\hline & & last & $29 \%$ & $9 \%$ & $23 \%$ & $17 \%$ \\
\hline & \multirow{2}{*}{$\begin{array}{c}\text { Non- } \\
\text { DP }\end{array}$} & alone & $38 \%$ & $40 \%$ & $41 \%$ & $55 \%$ \\
\hline & & last & $50 \%$ & $43 \%$ & $45 \%$ & $42 \%$ \\
\hline \multirow{4}{*}{ "donc" } & \multirow{2}{*}{ DP } & alone & $83 \%$ & $61 \%$ & $75 \%$ & $76 \%$ \\
\hline & & last & $12 \%$ & $18 \%$ & $12 \%$ & $11 \%$ \\
\hline & \multirow{2}{*}{$\begin{array}{c}\text { Non- } \\
\text { DP }\end{array}$} & alone & $68 \%$ & $59 \%$ & $74 \%$ & $64 \%$ \\
\hline & & last & $18 \%$ & $10 \%$ & $10 \%$ & $18 \%$ \\
\hline
\end{tabular}

Position in intonation group. According to Table 7, the studied words occur more often alone in prosodic groups when they are used as DPs than when non-DPs. The highest differences are observed for the word "alors" and "bon" while no substantial difference is observed for the word "donc". On the other hand, in non-DP functions, "alors" occurs more frequently in first position in prosodic groups while "bon" is more frequently in last position. In the interview and interaction styles, the word "alors" is more frequently alone when DP. The word "bon", when DP, is more frequently alone in all considered styles while, when non-DP, it is more frequent in last position. Finally, for the word "donc" there is a noteworthy difference between DP and non-DP functions 
in storytelling (more DPs alone than when non-DPs) while in the other styles there is either only a slight difference ('interaction') or no significant difference is found.

Other prosodic correlates such as the F0 slope, the duration of the last vowels, ... between the word and its neighbor words (preceding or following words) have been computed and studied. However, there is not enough place in the paper to present and comment their behavior. Nevertheless, such prosodic correlates have been used in the automatic classification tests that are presented in the next section.

\section{Automatic Classification and Detection}

In these experiments, prosodic correlates are used to automatically classify word occurrences as DP or non-DP. A neural network (NN) approach is used. For each of the three words, experiments are conducted using the Keras toolkit [37]. 60\% of the data are used for training the NN parameters, $10 \%$ for validation, and the remaining $30 \%$ are used for evaluating performance.

First experiments are conducted using prosodic features computed over the considered words and its neighbors (a few words before and after). The prosodic features include absolute and normalized values of the duration and energy of the last vowel of the words, F0 values at the end of the words and their slopes, the presence and the duration of pauses, ... The best classification results with these prosodic parameters are obtained by taking into account features associated to sequences of five to nine words centered over the considered word. As reported in Table 8, this leads to a correct classification rates ranging from $69 \%$ (for "alors") to $82 \%$ (for "bon"). With respect to DP detection, the F1-measure ranges from $78 \%$ (for "alors") to $88 \%$ (for "bon").

Table 8. Automatic classification and detection results using prosodic features.

\begin{tabular}{|c|c|c|c|c|}
\hline & Classification & \multicolumn{3}{|c|}{ DP detection } \\
\cline { 2 - 5 } & Correct & Recall & Precision & F1-measure \\
\hline "alors" & $69 \%$ & $81 \%$ & $75 \%$ & $78 \%$ \\
\hline "bon" & $82 \%$ & $90 \%$ & $86 \%$ & $88 \%$ \\
\hline "donc" & $71 \%$ & $79 \%$ & $84 \%$ & $81 \%$ \\
\hline
\end{tabular}

Another set of experiments have been conducted by considering only the F0 values (computed with the RAPT [38] approach of the SPTK toolkit [39]) over a time window centered over the considered word. Best results are obtained by considering a 3 to 5 second window. Classification and detection results are reported in Table 9. The correct classification rate ranges from $64 \%$ (for "alors") to $73 \%$ (for "donc"). With respect to DP detection, the F1-measure ranges from $75 \%$ (for "alors") to $84 \%$ (for "donc").

The results obtained with the F0 curve are almost as good as those achieved with the prosodic parameters (which include more information, as for example the durations of the last vowel of the words, presence of pauses, ...). Further classification experiments will consider combining these two sets of features. 
Table 9. Automatic classification and detection results using fundamental frequency values.

\begin{tabular}{|c|c|c|c|c|}
\hline & Classification & \multicolumn{3}{|c|}{ DP detection } \\
\cline { 2 - 5 } & Correct & Recall & Precision & F1-measure \\
\hline "alors" & $64 \%$ & $79 \%$ & $71 \%$ & $75 \%$ \\
\hline "bon" & $69 \%$ & $84 \%$ & $76 \%$ & $80 \%$ \\
\hline "donc" & $73 \%$ & $87 \%$ & $81 \%$ & $84 \%$ \\
\hline
\end{tabular}

\section{Conclusion}

In this paper, we have analyzed and discussed the distribution of discourse functions for three very frequent French words that can be used as discourse particles (DP) or not discourse particles (non-DP), over a large set of speech corpora. These corpora exhibit different speaking styles ranging from storytelling to highly spontaneous speech corresponding to oral interactions between speakers, and including intermediate styles such as prepared speech (from broadcast news) and spontaneous speech from interviews, dialogues and conversations.

For the three words ("alors", "bon" and "donc") considered in this study, a noticeable increase of their usage as a DP is observed from (1) storytelling (lowest percentage of DP usage), to (2) prepared speech, then to (3) interviews and conversations, and finally to (4) highly spontaneous speech observed in oral interactions between speakers (highest percentage of DP usage). A detailed study of the DP pragmatic function also show that the pragmatic usage vary across the corpora, and seems dependent on the spontaneity degree of the data.

Prosodic correlates of the words vary whether they are used as DPs or non-DPs. Moreover, in many cases, the distribution of the prosodic correlates also varies with respect to the spontaneity degree of the speech data. Automatic classification tests show that prosodic parameters (over a few word window) as well as the F0 curve (over a few second windows) carry significant information with respect to DP vs. non-DP function.

\section{Acknowledgements}

This work has been carried out in the framework of the ProsodCorpus operation supported by the CPER LCHN (Contrat Plan Etat Région "Langues, Connaissances et Humanités Numériques"). Some experiments presented in this paper have been carried out using the Grid' 5000 testbed, supported by a scientific interest group hosted by Inria and including CNRS, RENATER and several Universities as well as other organizations (see https://www.grid5000.fr).

\section{References}

1. Aijmer, K.: Understanding Pragmatic Markers. A variational pragmatic approach. Edinburgh: Edinburgh UP (2006). 
2. Bartkova, K., Bastien, A., Dargnat, M.: How to be a Discourse Particle ?. in Speech Prosody 2016, Boston, USA, pp. 859-863, (2016).

3. Degand, L., Fagard, B.: Alors between Discourse and Grammar: the Role of Syntactic Position. Function of Language, 18, pp. 19-56 (2011).

4. Hansen, M.B. M.: Particles at the Semantics- Pragmatics Interface: Synchronic and Diachronic Issues. Amsterdam: Elsevier (2008).

5. Wichmann, A., Simon-Vandenbergen, A.-A., Aijmer, K.: How prosody reflects semantic change: A synchronic case study of of course. In Davidse, K., Vandelanotte, L. and Cuyckens, H. (eds), Subjectification, Intersubjectification and Grammaticalization. Berlin: Mouton de Gruyter, pp. 103-154 (2010).

6. Brinton, L. J.: Pragmatic Markers in English. Grammaticalization and Discourse Functions. Berlin: De Gruyter (1996).

7. Degand, L., Cornillie, B. Pietrandrea, P. (eds): Discourse Markers and Modal Particles: Categorization and description. Amsterdam: John Benjamins (2013).

8. Dostie, G.: Pragmaticalisation et marqueurs discursifs. Liège: De Boeck/Duculot (2004).

9. Hansen, M.B. M.: The Function of Discourse Particles. Amsterdam: Benjamins (1998).

10. Ducrot, O.: Le Dire et le dit. Paris: Editions de Minuit (1984).

11. Kleiber, G.: Sémiotique de l'interjection. Langue française 161, pp. 10-23 (2006).

12. Sperber, D., Wilson, D.: Relevance: Communication and Cognition. Oxford: Blackwell, (1986).

13. Blakemore, D.: Semantic Constraints on Relevance. Oxford: Blackwell, (1987).

14. Denturck, E.: Étude des marqueurs discursifs - L'exemple de "quoi". Master Diss. Gent University (2008).

15. Fernandez-Vest, J.: Les particules énonciatives dans la construction du discours. Paris: Presses Universitaires de France (1994).

16. Galliano, S., Gravier, G., Chaubard, L.: The ESTER 2 evaluation campaign for rich transcription of French broadcasts. In INTERSPEECH 2009, 10th Annual Conf. of the Int. Speech Communication Association, Brighton, UK, pp. 2583-2586 (2009).

17. ORFEO project: http://www.projet-orfeo.fr/.

18. French oral narrative: http://frenchoralnarrative.qub.ac.uk.

19. CFPP2000 : http://cfpp2000.univ-paris3.fr/.

20. Branca-Rosoff, S., Fleury, S., Lefeuvre, F., Pires, M.: Discours sur la ville. Présentation du Corpus de Français Parlé Parisien des années 2000 (CFPP2000).

21. C-ORAL-ROM: http://lablita.dit.unifi.it/corpora/descriptions/coralrom/.

22. Cresti, E., do Nascimento, F. B., Moreno-Sandoval, A., Veronis, J., Martin, P., Choukri, K.: The C-ORAL-ROM CORPUS. A Multilingual Resource of Spontaneous Speech for Romance Languages. In. LREC 2004, $4^{\text {th }}$ Int. Conf. on Language Resources and Evaluation, Lisbon, Portugal (2004).

23. CRFP : http://www.up.univ-mrs.fr/delic/corpus/index.html.

24. Équipe Delic, "Autour du Corpus de référence du français parlé", Recherches sur le français parlé, $\mathrm{n}^{\circ} 18$, Publications de l'université de Provence, 265 p. (2004).

25. TUFS : http://www.tufs.ac.jp/ts/personal/ykawa/art/2014_Waseda_Corpus_TUFS.pdf

26. Valibel: http://www.uclouvain.be/81834.html.

27. CLAPI. http://clapi.ish-lyon.cnrs.fr/.

28. FLEURON : https://apps.atilf.fr/fleuron2/.

29. TCOF: http://www.cnrtl.fr/corpus/tcof/.

30. OFROM: http://www.unine.ch/ofrom.

31. Avanzi, M., Béguelin, M.-J., Diémoz, F.: Présentation du corpus OFROM - corpus oral de français de Suisse romande. Université de Neuchâtel, Switzerland, (2012-2015). 
32. Bechet, F., Maza, B., Bigouroux, N., Bazillon, T., El-Beze, M., De Mori, R., Arbillot, E.: DECODA: a call-centre human-human spoken conversation corpus. In LREC 2012, $8^{\text {th }}$ Int. Conf. on Language Resources and Evaluation, Istanbul, Turkey (2012).

33. Stede, M., Schmitz, B.: Discourse particles and discourse functions. Machine translation, 15(1-2), pp. 125-147 (2000).

34. Dargnat, M., Bartkova, K., Jouvet, D.: Discourse Particles In French: Prosodic Parameters Extraction and Analysis. In SLSP 2015, Int. Conf. on Statistical Language and Speech Processing, Budapest, Hungary (2015).

35. Bartkova, K., Jouvet, D.: Automatic detection of the prosodic structures of speech utterances. In SPECOM 2013, 15th, Int. Conf. on Speech and Computer. pp. 1-8. Springer, Berlin (2013).

36. Martin, P.: Prosodic and rhythmic structures in French. In Linguistics, vol.25, pp.925-949 (1987).

37. Keras: https://keras.io/.

38. Talkin, D.: A robust algorithm for pitch tracking (RAPT). In Speech Coding and Synthesis, W. B. Kleijn and K. K. Paliwal, Eds. Elsevier, pp. 495-518 (1995).

39. SPTK: http://sp-tk.sourceforge.net/. 